\title{
Determination of Swell Potential of Soils using Cole in Panyam, North - Central Nigeria
}

\author{
A. A. Umbugadu, M. I. Ancho, and Nghargbu K'tso
}

\section{ABSTRACT}

\begin{abstract}
Swell potential of soils from parts of Panyam, North - Central Nigeria were investigated covering 72 square kilometres within latitudes N9021' and N9026' and longitudes $9011^{\prime} \mathrm{E}$ and $\mathrm{9015}^{\prime} 30^{\prime \prime} \mathrm{E}$. With the increase of civil engineering constructions and the scramble for limited portions of competent soils for such constructions, there is an urgent need in a developing nation to study and characterize such soils based on its geotechnical properties. The geotechnical studies include twenty soil samples taken within the $1.5 \mathrm{~m}$ depth with the aim of determining the swell potential in order to give appropriate guide to any civil engineering design and construction. The direct method of soil analysis which is the coefficient of linear extensibility (COLE), which ranges from $0.02-0.17$ was used for the study. COLE Values greater than 0.06 , were considered to be critical for most civil engineering design and constructions. Most of the samples studied were considered not safe for bungalows and some infrastructure without proper safety measures carried out to improve upon it.
\end{abstract}

Keywords: Constructions, shrinkage, soil, swell.

\section{INTRODUCTION}

Moisture content determines the amount by which the ground can shrink and/or swell near the surface [1], [2]. Clay soils have the tendency to absorb large quantities of water and they can also release water depending on the climate (especially in the tropics) causing shrink - swell behaviour.

Expansive soils cause problems to geotechnical designs and constructions [3]. This is as a result of their ability to absorb and release water at certain environmental conditions (Fig. 1). They can increase in volume beyond the perceptible or threshold limits and as such can cause damages to mostly buildings and roads. Because of the changes in behaviour, this normally results in differential settling causing cracks to shallow foundations, pavements etc. This study becomes useful because of the extent of damage of engineering structures constructed on such soils.

Reference [4] Posited that Coefficient of Linear Extensibility (COLE) of soil can be used to describe the shrink or swell potentiality of soils clod giving the relative potentials of soils to either shrink or swell.

Most soils in the area are problematic and engineering constructions are founded on such clay - rich soils which are of significant hazard due to their ability to shrink or swell with changes in moisture content. This study is important particularly in the area studied because of infrastructural development and other environmental factors like global warming, deforestation, desertification, etc, access to land for both domestic and industrial uses become difficult because properties. of Nigeria (Fig. 2).
Published Online: September 13, 2021

ISSN: $2684-446 \mathrm{X}$

DOI : $10.24018 /$ ejgeo.2021.2.5.164

\section{A. A. Umbugadu*}

Department of Geology \& Mining, Nasarawa State University, PMB 1022, Keffi, Nigeria.

(e-mail: umbugaduallu@nsuk.edu.ng)

M. I. Ancho

Department of Geology \&Mining, Nasarawa State University, PMB 1022, Keffi, Nigeria

(e-mail: mozisbubo@gmail.com)

Nghargbu K'tso

Department of Geology \&Mining, Nasarawa State University, PMB 1022, Keffi, Nigeria

(e-mail: nghargtbu ${ }^{\circledR}$ gmail.com)

*Corresponding Author

the area is a rural agrarian community with poor infrastructural development and hence frequent clashes about land ownership in such parts of the country becomes imminent. With the lack of technical know - how to improve on the problematic soils, the available 'suitable' soil is limited and often not always suitable for high quality engineering design and construction, hence the need to improve on its

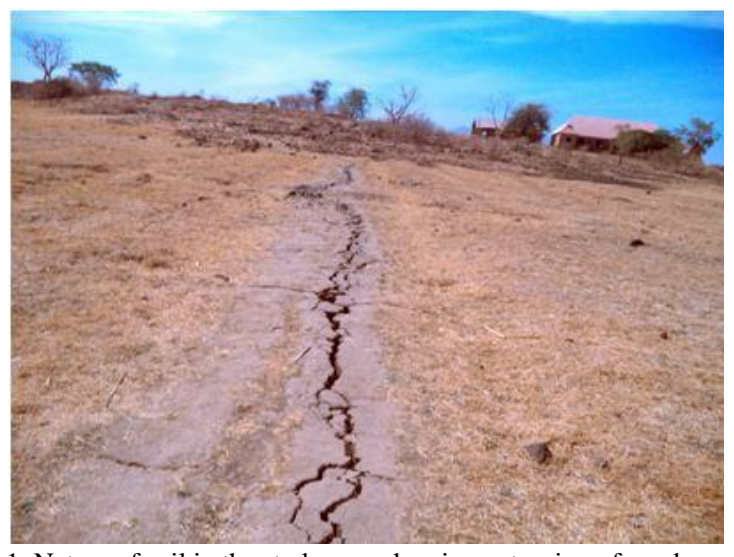

Fig. 1. Nature of soil in the study area showing extension of crack as a result of swelling.

The study area is in Panyam village, north-central Nigeria. It is located between latitudes N9 $21^{\prime}$ and N9 ${ }^{\circ} 26^{\prime}$, longitudes $9^{\circ} 11^{\prime} \mathrm{E}$ and $9^{\circ} 15^{\prime} 30^{\prime \prime} \mathrm{E}$ and falls within the Basement Complex 


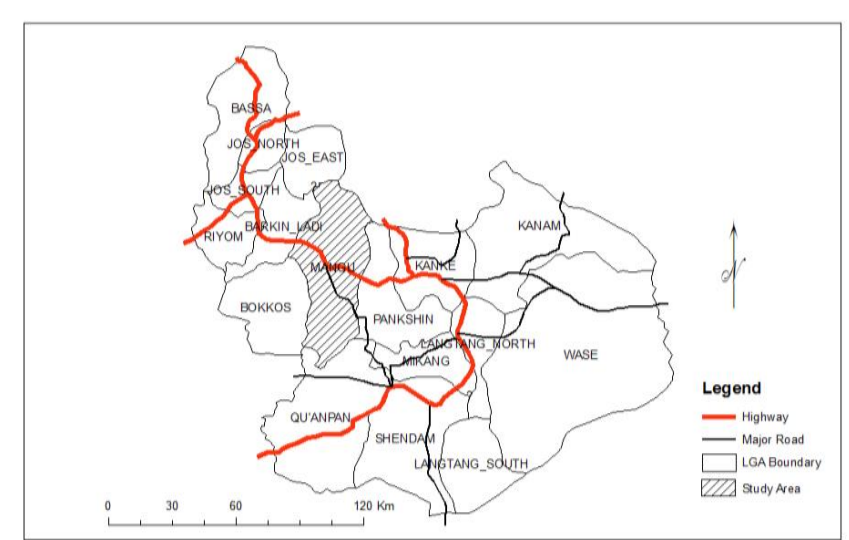

Fig. 2. Location map of the area.

\section{Methodology}

Soil samples derived from the weathering of granites and basalts were collected in the study area; Mangu, North central Nigeria. Sampling sites was carefully selected based on physiographic zones/features of the area; high ground and plains [5] with forty (40) disturbed samples collected at $1.5 \mathrm{~m}$ depth over 72 square kilometres to properly represent a wide variation in swelling properties and different parent materials that would constitute mainly of volcanic and basement rocks (Fig. 3a \& b). The samples were collected by random sampling adhering to the [6] method of sampling.

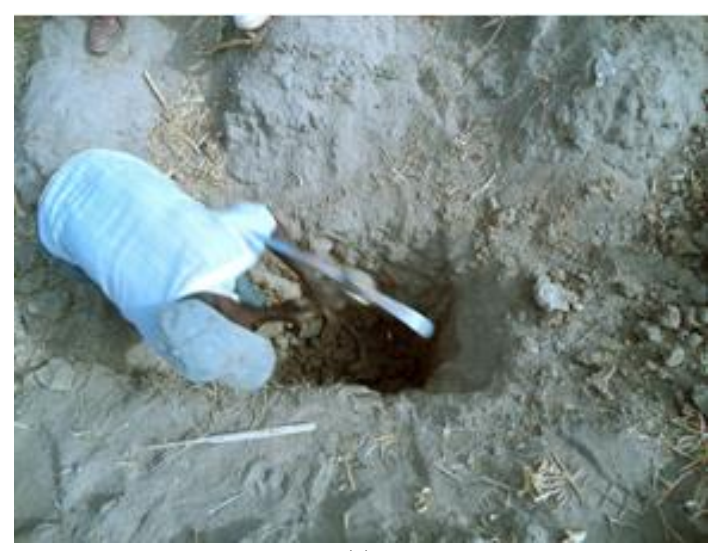

(a)

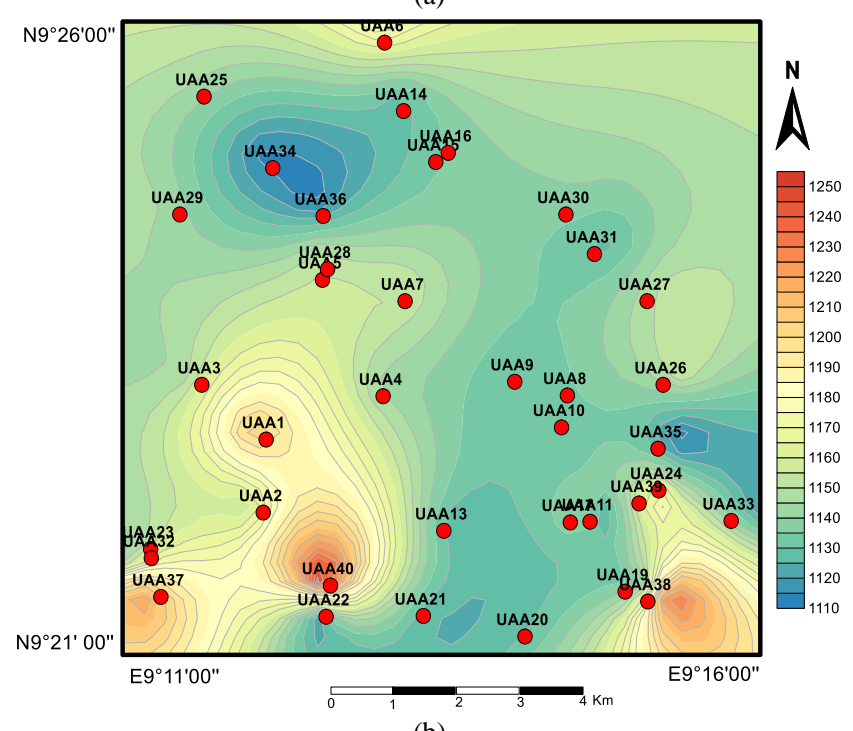

(b)

Fig. 3. (a) Sampling of disturbed soil in the study. (b) Sampling location map.
Samples of soils of the Quaternary period from Mangu, Central Nigeria were taken from highway construction sites and near residential buildings to study the effect of the property on such engineering construction. These materials as presented in Table I, with liquid limit of up to $80 \%$ and plastic limit up to $43 \%$ were as a result of the presence of some clay minerals particularly smectite and swelling chlorite in the samples.

The measure of the swell behaviour of the soils given as; Coefficient of Linear Extensibility (COLE) was measured using the method adopted by [7] from where the Volumetric Shrinkage (VS) was calculated from the equation below:

$$
\mathrm{VS}=\left[(\mathrm{COLE} \text { value }+1)^{3}-1\right] \times 100
$$

\section{RESULTS}

Geologically, the area is composed of four major rock units, which chronologically can be listed as Granite gneiss, fine/medium grained biotite granite, older and newer basalts (Fig. 4). Spatially, the newer basalt occupies about $85 \%$ of the area covering the Northern portion of the studied area. The fine to medium grained biotite granite occupies about $10 \%$ of the area occurring along the entire southern portion of the studied area. The granite gneiss which covers about $4 \%$ occurs along the southwestern part of the area while the remaining $1 \%$ of the area far north is occupied by the older basalt.

The older and younger basalts are Tertiary and Quaternary volcanics, respectively. The basalts are distinguished on the basis of their period of emplacement and textural differences [8]. The older basalts occur as decomposed boulders, plugs or dome-like outcrops, while the newer basalts occur as cones and lava flows.
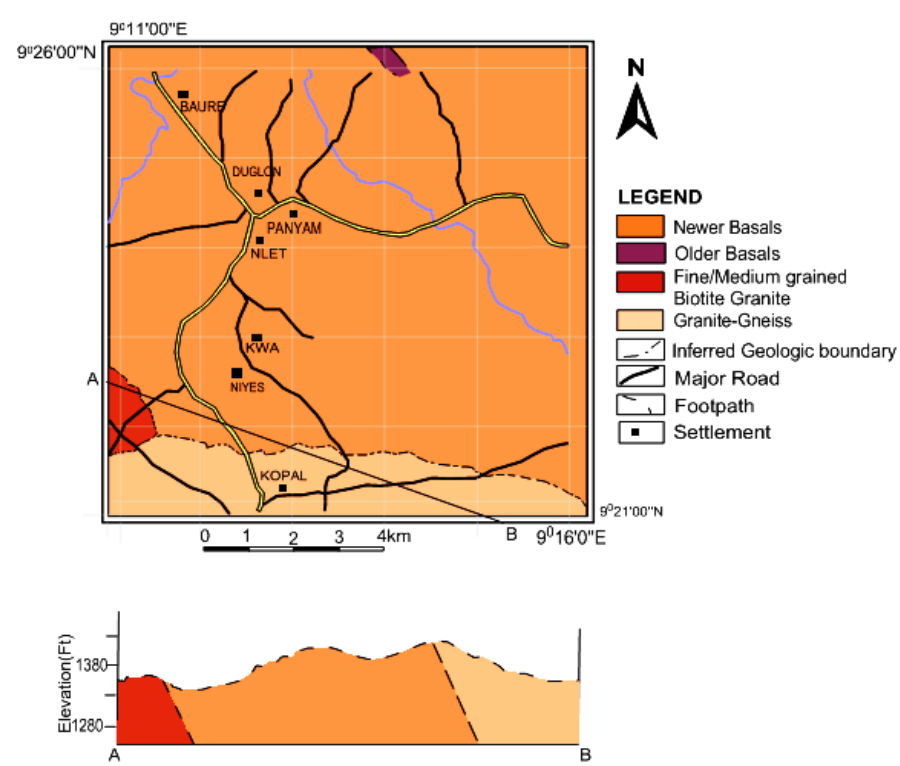

Fig. 4. Geological Map of the Area.

Soil samples constitute chiefly of kaolinite and smectite. The samples have wide range of swelling potentials due to the varying minerals contained in them and the areas it was sampled. Table I below gives a summary of the swelling characteristics, coefficient of linear extensibility and volumetric shrinkage. Atterberg limits with liquid limit (LL), 
plastic Limit (PL). Particle size distribution and compaction characteristics with optimum moisture content (OMC) and maximum dry density (MDD).

Coefficient of Linear Extensibility (COLE), Volumetric Shrinkage (VS), Optimum Moisture Content (OMC), Maximum Dry Density (MDD), Liquid Limit (LL), Plastic Limit (PL) and Plasticity Index (PI)
Researchers like [3], [9] have discussed extensively linking the swell/shrink behaviour of such soils with mineralogy, water content, and clay content. Reference [10] was of the opinion that the increase in COLE values with depths at surface horizons was as a result of the decrease in organic matter. According to [11], strong and reliable correlation based on linear relationship, has been found connecting swell percent with initial state factors like clay content and COLE.

TABLE I: SWELling CHARACTERISTICS, ATTERBERG LIMITS AND PARTICLE SIZE DisTRIBUTION OF SOIL TYPES OF THE AREA

\begin{tabular}{|c|c|c|c|c|c|c|c|c|c|c|}
\hline \multirow[b]{2}{*}{$\begin{array}{l}\text { Sample } \\
\text { ID }\end{array}$} & \multicolumn{2}{|c|}{ Swelling Characteristics } & \multicolumn{3}{|c|}{ Consistency Limits } & \multicolumn{3}{|c|}{ Particle Size Analysis } & \multicolumn{2}{|c|}{ Compaction } \\
\hline & COLE & VS & $\begin{array}{l}\mathrm{LL} \\
(\%)\end{array}$ & $\begin{array}{l}\mathrm{PL} \\
(\%)\end{array}$ & $\begin{array}{c}\mathrm{PI} \\
(\%)\end{array}$ & $\begin{array}{c}\text { Sand } \\
(\%)\end{array}$ & $\begin{array}{l}\text { Silt } \\
(\%)\end{array}$ & $\begin{array}{l}\text { Clay } \\
(\%)\end{array}$ & $\mathrm{OMC}(\%)$ & $\begin{array}{l}\mathrm{MDD} \\
\left(\mathrm{g} / \mathrm{M}^{3}\right)\end{array}$ \\
\hline UAA 2 & 0.040 & 12.486 & 40 & 24 & 16 & 20 & 47 & 33 & 20.0 & 1.54 \\
\hline UAA 3 & 0.021 & 06.433 & 37 & 25 & 12 & 08 & 68 & 24 & 24.5 & 1.54 \\
\hline UAA 4 & 0.039 & 12.162 & 42 & 21 & 21 & 11 & 57 & 31 & 22.5 & 1.52 \\
\hline UAA 5 & 0.034 & 10.550 & 54 & 41 & 13 & 16 & 61 & 23 & 21.5 & 1.56 \\
\hline UAA 6 & 0.036 & 11.257 & 30 & 20 & 10 & 14 & 62 & 20 & 15.0 & 1.80 \\
\hline UAA 9 & 0.130 & 06.120 & 65 & 46 & 19 & 10 & 33 & 57 & 28.5 & 1.44 \\
\hline UAA 14 & 0.152 & 42.003 & 65 & 33 & 22 & 08 & 21 & 70 & 31.0 & 1.43 \\
\hline UAA 15 & 0.166 & 58.524 & 70 & 45 & 25 & 10 & 18 & 72 & 30.0 & 1.40 \\
\hline UAA 16 & 0.022 & 59.341 & 66 & 39 & 27 & 12 & 65 & 25 & 20.0 & 1.62 \\
\hline UAA 24 & 0.168 & 59.341 & 40 & 20 & 20 & 09 & 15 & 76 & 25.7 & 1.47 \\
\hline UAA 25 & 0.082 & 26.672 & 46 & 26 & 20 & 10 & 46 & 44 & 26.0 & 1.46 \\
\hline UAA 26 & 0.079 & 25.621 & 60 & 44 & 16 & 12 & 45 & 43 & 28.0 & 1.47 \\
\hline UAA 27 & 0.147 & 50.900 & 47 & 26 & 21 & 08 & 27 & 65 & 32.5 & 1.44 \\
\hline UAA 29 & 0.079 & 25.621 & 43 & 22 & 21 & 07 & 50 & 43 & 26.0 & 1.44 \\
\hline UAA 30 & 0.108 & 36.025 & 49 & 26 & 23 & 10 & 38 & 52 & 27.1 & 1.44 \\
\hline UAA 31 & 0.108 & 36.025 & 50 & 34 & 26 & 10 & 38 & 52 & 13.8 & 1.84 \\
\hline UAA 33 & 0.036 & 11.193 & 42 & 20 & 22 & 13 & 58 & 29 & 19.8 & 1.55 \\
\hline UAA 34 & 0.085 & 27.728 & 52 & 31 & 21 & 06 & 45 & 45 & 16.2 & 1.77 \\
\hline UAA 35 & 0.018 & 05.497 & 62 & 44 & 18 & 12 & 70 & 18 & 26.8 & 1.45 \\
\hline UAA 36 & 0.080 & 25.971 & 54 & 32 & 22 & 06 & 49 & 43 & 25.80 & 1.48 \\
\hline
\end{tabular}

\section{DISCUSSION}

COLE is a good indicator of field behaviour of soils which is used for characterization in terms of volume and shrink swell potential. Table II categorized soils shrink - swell behaviour based on their COLE values.

\begin{tabular}{cc} 
TABLE II: SCHAFER AND SINGER COLE RATING \\
\cline { 2 - 2 } COLE & Rating \\
\hline $0.00-0.03$ & Slight \\
$0.03-0.06$ & Moderate \\
$0.06-0.09$ & Severe \\
$>0.09$ & Very severe \\
\hline
\end{tabular}

Soils within the study area reflect the different ratings as outlined by [9]. Three soil samples, UAA3, UAA 16 and UAA 35 fall under the slight with minimum or no impact to infrastructure that were constructed around the vicinity. Samples UAA2, UAA4, UAA5, UAA6 and UAA 33 have moderate impact on infrastructures of the area according to the COLE values and rating in Table II. The most intense impact are those infrastructures constructed on areas where the soils are gotten from UAA25, UAA26, UAA29, UAA34, UAA 36, UAA 9, UAA 15, UAA24, UAA 27 and UAA 30 where the rating is severe and very severe. The COLE values as plotted shows a good correlation with the clay content. The higher the clay content the higher the value of COLE (Fig. 5).

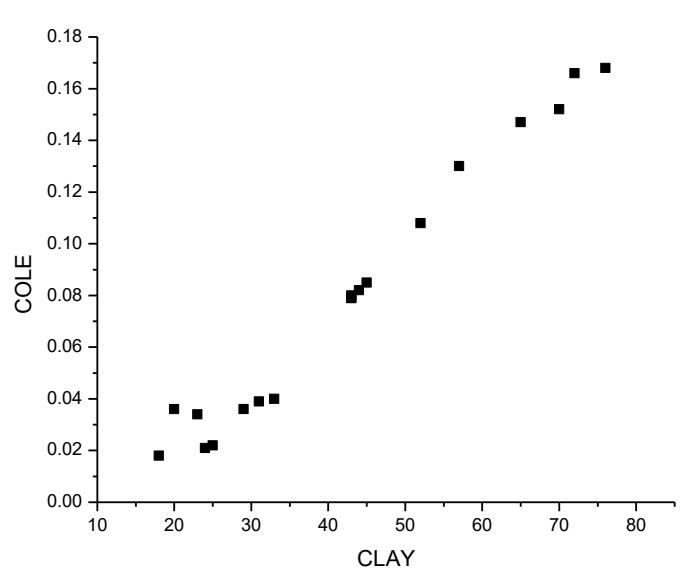

Fig. 5. Plot showing the relation of clay fraction with COLE of soils in the study area.

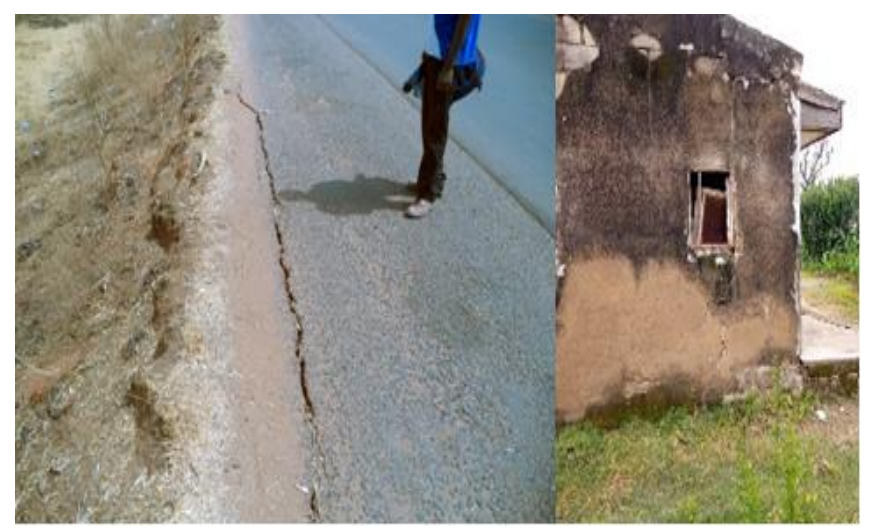

Fig. 6. Impact of COLE on shrink - swell behaviour of soils in the area. 


\section{CONCLUSION}

COLE, which is a direct method, used to predict soil swell - shrink behaviour of soils, was analysed for soils of the area.Ten out of twenty samples analysed, showed severe to very severe rating as impact to infrastructure in the area, and hence linked to the infrastructural collapse of foundation in such areas. Even though most of the southern portion of the area was mostly clay, the COLE values correlate with the nature of clay minerals found within the area. Areas outlined as having swelling clays like Illite fall under the very severe and severe swelling category while those clays that occupied predominantly the southern portion of the area which are kaolinite, are the ones that fall under the moderate swelling category.

\section{REFERENCES}

[1] P.G. Biddle. Tree roots and foundations, Arboriculture Research and Information Note 42/98/EXT, 1998.

[2] R. Driscoll. The influence of vegetation on the swelling and shrinking of clay soils in Britain. Geotechnique, 1983, (33) 93-105

[3] F. H. Chen. (1988). Foundations on Expansive Soils. Elsevier, Amsterdam, the Netherlands.

[4] M. M. E. Zumrawi. Swelling Potential of Compacted Expansive Soils. International Journal of Engineering Research and Technology. 2013, Vol. 23) 1-6.

[5] Food and Agricultural Organization, 1977. Guidelines for soil profile Descriptions ( $2^{\text {nd }}$ edition). Rome, 66.

[6] R. Driscoll\&M. Crilly. Subsidence damage to domestic buildings. Lessons learned and questions asked. Building Research Establishment, London, 2000.

[7] W. G. Holtz \& H. J. Gibbs. Engineering Properties of Expansive Clays. Transactions of the American Society of Civil Engineers, 1956, (121), 641-663.

[8] D. E. McCormack, L. P. Wilding. Soil Properties Influencing Swelling in Cranfield and Geeburg soils. Soil Sci. Soc. Am. Proc. 1975, 39, 496502.

[9] P. J. Thomas, J. C. Baker, L. W. Zelazny.An expansive soil index for predicting shrink - swell potential. Soil Sci. Soc. Am. J.2000, 64, 268 274.

[10] F. H. Chen. The use of pies to prevent the uplifting of lightly loaded structure founded on expansive soil. Concluding proceedings engineering effects of moisture change in soils, International Research and Engineering Conference on expansive clay soils. A and M. Texas, $1965,152-171$.

[11] A. Sridharan \& Y. Gurtug. Swelling Behaviour of Compacted Fine grained soils. Engineering Geology Journal, 2004, 72, 9-18.

A. A. Umbugadu holds a $\mathrm{PhD}$ in Engineering Geology from the University of Nigeria, Nsukka. He is currently a Lecturer at the Department of Geology and Mining, Nasarawa State University, Keffi, Nigeria.

M. I. Ancho holds a Masters Degree in Hydrogeology from the Federal University of Technology Minna, Nigeria. He is currently a Lecturer with the Department of Geology and Mining, Nasarawa State University, Keffi, Nigeria.

Nghargbu K'tso holds a PhD in Medical Geology from the Ahmadu Bello University, Zaria, Nigeria. He is currently a Lecturer with the Department of Geology and Mining, Nasarawa State University, Keffi, Nigeria. 